Article

\title{
Biological Control of Thielaviopsis paradoxa and Colletotrichum gloeosporioides by the Extracellular Enzymes of Wickerhamomyces anomalus
}

\author{
Luis Fernando Zepeda-Giraud ${ }^{1}(0)$, Dario Rafael Olicón-Hernández ${ }^{1,2}{ }^{1}$, Juan Pablo Pardo ${ }^{2}$, \\ Minerva Georgina Araiza Villanueva ${ }^{1,2}$ and Guadalupe Guerra-Sánchez ${ }^{1, *}$ \\ 1 Departamento de Microbiología, Escuela Nacional de Ciencias Biológicas, Instituto Politécnico Nacional, \\ Prolongación de Carpio y Plan de Ayala S/N, Col. Sto. Tomas, Alcaldía Miguel Hidalgo, \\ Ciudad de México CP 11340, Mexico; lfzgiraud@gmail.com (L.F.Z.-G.); \\ magnadroh@hotmail.com (D.R.O.-H.); minegav@hotmail.com (M.G.A.V.) \\ 2 Departamento de Bioquímica, Facultad de Medicina, Universidad Nacional Autónoma de México, \\ Circuito Interior S/N, Ciudad Universitaria, Ciudad de México CP 04510, Mexico; pardov@bq.unam.mx \\ * Correspondence: lupegs@hotmail.com; Tel.: +52-55-57296000 (ext. 62339)
}

Received: 6 July 2020; Accepted: 21 July 2020; Published: 2 August 2020

\begin{abstract}
An alternative to chemical fungicides in post-harvest diseases are the use of biocontrol agents and their extracellular products against phytopathogens. Two relevant agents in post-harvest infections are Thielaviopsis paradoxa and Colletotrichum gloeosporioides, causing large economic losses in cacao, pineapple, and avocado during storage. In this work, we evaluated the effect of Wickerhamomyces anomalus, an effective biocontrol agent, against these filamentous fungi, focusing on the production of extracellular enzymes and their effect on fungal growth and germination. Moreover, we evaluated the use of inactivated fungal biomass as an inducer in complete (Potato Dextrose Agar and Yeast Peptone Dextrose) and minimal culture media. The antagonistic effect of $W$ anomalus on the growth of both phytopathogens was also studied. The extracellular enzymes in YPD cultures, using T. paradoxa inactivated biomass as the best inducer, were capable of inhibiting the germination of both phytopathogens. In minimal media, only the production of a $30 \mathrm{kDa}$ glucanase with activity against laminarin was observed. The enzyme was effective against the spore germination of T. paradoxa. In post-harvest crop protection tests, growth inhibition of T. paradoxa was observed using the cell-free enzyme extract, which is a promising system to protect cocoa fruits from T. paradoxa during post-harvest.
\end{abstract}

Keywords: glucanase; Wickerhamomyces anomalus; biocontrol; Thielaviopsis paradoxa; Colletotricum gloeoesporioides

\section{Introduction}

The protection of post-harvest agricultural products, such as crops, fruits and vegetables, from the attack of phytopathogenic fungi, represents an unsolved problem [1,2]. Worldwide, infections caused by fungal phytopathogens account for $20-25 \%$ of the losses in harvested fruits and vegetables, with a strong impact on product quality [3]. The most common practice to prevent these diseases is the application of different synthetic fungicides that inhibit the growth of pathogens [4]. Some fungicides alter the cell membrane of microorganisms and its biological functions; other processes affected by these compounds are the synthesis of nucleic acids and proteins, signal transduction, cell division, and respiration [5]. However, some of the most important concerns about the use of these antifungal compounds are the negative environmental impacts, the potential carcinogenic effect, the harmful influence on other beneficial microorganisms, and the outbreak of resistance to chemicals in phytopathogenic agents [4]. 
In recent years, the use of natural compounds has gained interest as an alternative to chemical strategies. Biocontrol is a versatile option with potential to be applied in the field [2].

Biocontrol or biological control is the use of different organisms and natural substances as agents against phytopathogenic microorganisms [6]. Biocontrol strategies involve the use of innocuous living microorganisms, organic molecules, oils, chitin-hydrolysis products, hydrolytic enzymes, peptides, and carbohydrates, among others [3,7]. In the context of microorganisms, bacteria and filamentous fungi, such as Trichoderma spp., have been studied as potential biocontrol tools [8,9]. Yeasts are also one of the most utilized groups because of their potent and versatile antagonism against phytopathogens [2]. To prevent host infection, yeast antagonism uses different synergistic mechanisms: mycoparasitism, competition for space and nutrients, induction of host resistance mechanisms, secretion of metabolites, toxin production, the release of volatile substances, and the generation of extracellular hydrolytic enzymes, especially those that hydrolyze the cell wall, such as glucanases and chitinases $[10,11]$.

The main target of these enzymes is the fungal cell wall, which contains structural polymers like chitin and $\beta$-glucan $[4,12]$. The main effects of the hydrolytic activity of these enzymes on the cell wall include: (1) generation of simple carbon compounds that are used as a source of carbon and nitrogen by the biocontrol agent, (2) disruption of the integrity of the cell wall and the subsequent death of the phytopathogen, and (3) an inhibitory effect on the germination of spores and conidia of filamentous fungi $[13,14]$.

Wickerhamomyces anomalus is an attractive biotechnological yeast that has been used for food biopreservation, bioremediation, the production of biofuels, and the production of recombinant enzymes [15-17]. As a biocontrol microorganism, this ascomycete protects different agricultural products against the action of different phytopathogens, i.e., Botrytis cinerea, Penicillium roqueforti, and Aspergillus flavus [18-21]. The mechanisms by which $W$. anomalus achieves this antagonistic effect is associated with mycoparasitism, the production of volatile compounds, and the presence of hydrolytic enzymes [22,23]. Although the use and effectiveness of this yeast as an antagonistic agent is well established, studies on the use and production of hydrolytic enzymes using unconventional carbon sources are of interest to expand its spectrum as a biocontrol agent.

In the context of phytopathogenic agents of global interest, a large number of filamentous fungi cause damage to various crops; however, Colletotrichum gloeosporioides and Thielaviopsis paradoxa are two of the most relevant agents since they attack a wide variety of fruits and vegetables leading to significant economic losses [24-26]. C. gloeosporioides is the etiological agent of anthracnose, a disease characterized by the presence of sunken necrotic lesions with concentric orange rings in the plant. This pathogen affects a range of tropical, subtropical, and temperate fruits, crops, and ornamental plants, such as avocado (Persea americana), tree tomato (Solanum betaceum), and mango (Mangifera indica) [27]. C. gloeosporioides is responsible for up to $60 \%$ of the losses in the harvest of these crops [27]. T. paradoxa is a soilborne plant pathogen that causes diseases in the date palm (Phoenix dactylifera), pineapple (Ananas comosus), coconut (Cocos nucifera), agave (Agave tequilana), and cacao (Theobroma cacao) in the USA, Brazil, and México. This pathogen represents more than $23 \%$ of the losses in some of these crops [28].

The goals of the present work were as follows: (1) To evaluate the antagonistic effects of $W$. anomalus against Thielaviopsis paradoxa and Colletotrichum gloeosporioides using whole cells with different culture media, and the hydrolytic enzymes from cell-free extracts; (2) To find the conditions for the production of cell wall hydrolytic enzymes, focusing on glucanases and chitinases, using inactivated mycelia as inducer, and following their expression pattern; and (3) To evaluate the inhibitory effect of the glucanase produced by W. anomalus against $C$. gloeosporioides and T. paradoxa.

\section{Materials and Methods}

\subsection{Strains and Culture Conditions}

C. gloeosporioides was isolated from anthracnose-infected avocados, while T. paradoxa was obtained from infected cocoa pods. The ATCC strain of $W$. anomalus was obtained from CINVESTAV-IPN and is 
registered in the NCBI database as CDBB-L-1446. The strains were maintained on commercial Potato Dextrose Agar (PDA) (BD Difco ${ }^{\mathrm{TM}}$, Franklin Lakes, NJ, USA). The antagonistic effect of W. anomalus was tested in PDA, Yeast Peptone Dextrose (YPD) (2\% yeast extract, $2 \%$ peptone, and $2 \%$ dextrose), and Minimal Medium (MM) composed of $0.3 \%$ dextrose, $0.3 \% \mathrm{NaNO}_{3}$, and $0.3 \%$ of salt solution (16 g/L monobasic potassium phosphate, $4 \mathrm{~g} / \mathrm{L}$ sodium sulfate, $2 \mathrm{~g} / \mathrm{L}$ potassium chloride, and $1 \mathrm{~g} / \mathrm{L}$ of calcium chloride).

\subsection{Antagonism Tests Using W. anomalus Whole-Cells}

The antagonistic effect of yeast against the growth of phytopathogens was evaluated in solid and liquid media. In the first case, Petri dishes with PDA, YPD, and MM (1.5\% agar) were inoculated using a modification of the method described by Felestrino et al. [29], which can be summarized in two steps. First, a $6 \mathrm{~mm}$ disc saturated with the mycelium of the phytopathogen was placed in the center of the dish. Then, a cell suspension of $W$. anomalus with 1.0 unit of optical density at $600 \mathrm{~nm}$ $\left(\mathrm{OD}_{600 \mathrm{~nm}}\right)$ was placed at the periphery of the plate, about $2.5 \mathrm{~cm}$ away from the central disc. The Petri dishes were incubated at $28^{\circ} \mathrm{C}$ for 72 to $120 \mathrm{~h}$, and the radial growth was measured to evaluate the degree of inhibition. This determination was made by measuring the diameter of the circle defined by the radial growth of the fungus in the Petri dish, for both the control and the media containing the antagonist. The control represented $100 \%$ of the growth. To obtain the inhibition percentage, the percentage representing the diameter of the growth of the fungi with the antagonist compared to the control was calculated. Five replicates were made for each media condition for subsequent statistical validation using the software sp14 (SYSTAT Software, Inc. San Jose, CA, USA).

For growth inhibition in a liquid medium, the effect on spore germination was evaluated. Flasks with $50 \mathrm{~mL}$ of the three different media were inoculated simultaneously with five units of $\mathrm{OD}_{600 \mathrm{~nm}}$ (to get an initial $\mathrm{OD}_{600 \mathrm{~nm}}=0.1$, one $\mathrm{OD}_{600}$ of $W$. anumalus corresponds to $4.2 \times 10^{7}$ cells $/ \mathrm{mL}$ ) of W. anomalus obtained from a $20 \mathrm{~h}$ culture on a Petri dish and with $1.25 \times 10^{6}$ spores from a suspension of the phytopathogen (dual-culture). The flasks were incubated at $28^{\circ} \mathrm{C}$ and $120 \mathrm{rpm}$ for $72 \mathrm{~h}$. The germination of the spores was observed by optical microscopy at $40 \times$, and germination was qualitatively evaluated. The experiments were performed in triplicate.

Additionally, the effects on the integrity of the cell wall and damage to the mycelia were evaluated. In this case, $1.25 \times 10^{6}$ spores from a suspension of the phytopathogen were grown in $50 \mathrm{~mL}$ of each medium, for $72 \mathrm{~h}$ at $28^{\circ} \mathrm{C}$ and $120 \mathrm{rpm}$ without the biocontrol agent. After this time, five units of $\mathrm{OD}_{600 \mathrm{~nm}}$ of $W$. anomalus were inoculated, and cultures were further incubated for another $72 \mathrm{~h}$ in the same conditions. To evaluate the effect on cell morphology, an aliquot was withdrawn and stained with lactophenol blue to observe the structural damage under an optical microscope at a magnification of $40 \times$ [30]. The experiments were performed in triplicate.

\subsection{Determination of the Influence of Chitinases and Glucanases as Part of the Antagonistic Effect. Enzymatic Production Systems}

\subsubsection{Analytical Methods. Enzyme Activity}

Glucanase activity was measured according to the method described by Ramada et al. 2010 [31] with some modifications regarding the incubation time and temperature. In a $200 \mu \mathrm{L}$ PCR tube, $10 \mu \mathrm{L}$ of the enzyme sample was mixed with $20 \mu \mathrm{L}$ of $0.75 \%$ laminarin in $50 \mathrm{mM}$ sodium citrate buffer, $\mathrm{pH} 5.0$. The samples were incubated in a thermal cycler (techne TC-3000X) for $1 \mathrm{~h}$ at $37^{\circ} \mathrm{C}$, and then the reaction was stopped with $100 \mu \mathrm{L}$ of dinitrosalicylic acid (DNS) reagent [32], followed by heating the tubes for five minutes at $96^{\circ} \mathrm{C}$. Finally, $100 \mu \mathrm{L}$ of the content was transferred to a 96-well plate, and the absorbance was read at $540 \mathrm{~nm}$. The amount of glucose released was obtained from a glucose standard curve. One unit of glucanase was defined as the quantity of enzyme necessary to produce $1 \mu \mathrm{mol}$ of glucose per hour under the reaction conditions. The experiments were carried out in triplicate. 
Chitinase activity was measured using a modification of the glucanase method. Briefly, in a $200 \mu \mathrm{L}$ PCR tube, $60 \mu \mathrm{L}$ of the enzyme samples were mixed with $140 \mu \mathrm{L}$ of $0.5 \%$ colloidal chitin, followed by an $1 \mathrm{~h}$ incubation at $37^{\circ} \mathrm{C}$ in a thermal cycler. After this, samples were centrifuged at $10,000 \mathrm{rpm}$ at $4{ }^{\circ} \mathrm{C}$ to separate the colloidal chitin, and $30 \mu \mathrm{L}$ of the supernatant was transferred to new tubes, mixed with $100 \mu \mathrm{L}$ of the DNS reagent, and heated in the thermal cycler for five minutes at $96{ }^{\circ} \mathrm{C}$. Finally, $100 \mu \mathrm{L}$ of the samples were transferred to a 96-well plate, and the absorbance was read at $540 \mathrm{~nm}$. The amount of the N-acetyl-glucosamine (NAG) released was determined by interpolation with a standard NAG curve. One unit of chitinase was defined as the quantity of enzyme necessary to produce $1 \mu \mathrm{mol}$ of NAG per hour under the reaction conditions.

\subsubsection{Inducer Preparation for the Production of the Hydrolytic Enzymes}

Three different inducers were tested for the production of the enzymes: (1) The natural substrate chitin; (2) The inactivated biomass of T. paradoxa; and (3) The inactivated biomass of $C$. gloeosporioides. It is important to note that, in contrast to chitinases, a specific inducer for glucanases was not used due to the complexity of $\beta$-glucans. The biomasses of the phytopathogens were chosen due to the constitution of their cell walls [33].

For the conventional inducer of chitinase, colloidal chitin was prepared by mixing $10 \mathrm{~g}$ of commercial chitin (Sigma-Aldrich, St. Louis, MO, USA) with $100 \mathrm{~mL}$ of concentrated $\mathrm{HCl}$ and incubating at room temperature for two hours under slow stirring. Subsequently, one liter of $95 \%$ cold ethanol was added, and the mixture was incubated overnight at room temperature under rapid stirring. The resulting mixture was filtered, and the paste was washed several times with $0.1 \mathrm{M}$ phosphate buffer at $\mathrm{pH} 7$ and centrifuged to concentrate it, until the $\mathrm{pH}$ of the sample reached a value of 7.0. The paste was sterilized and kept at $4{ }^{\circ} \mathrm{C}$ until further use [34].

For the production of phytopathogen biomass and its use as inducer, fungi mycelia were obtained after $72 \mathrm{~h}$ culture in $\mathrm{PDB}$, concentrated by filtration, washed with distilled water, centrifuged, dried on an oven at $35^{\circ} \mathrm{C}$ and stored at $-20^{\circ} \mathrm{C}$ until use.

\subsubsection{Production of Hydrolytic Enzymes. Evaluation of Expression Pattern}

W. anomalus was grown for $24 \mathrm{~h}$ on PDA plates under the conditions described before. After this time, the biomass was collected and washed twice with sterile water. To avoid medium interferences, at this stage, only YPD and MM broths were used. Flasks with $30 \mathrm{~mL}$ of each medium were prepared with the addition of $0.5 \%(w / v)$ of the different inducers and inoculated with $W$. anomalus cells to give an initial $\mathrm{OD}_{600 \mathrm{~nm}}$ of 0.1 . Flasks were cultured for $24 \mathrm{~h}$ at $28^{\circ} \mathrm{C}$ and $120 \mathrm{rpm}$. The biomass was separated by centrifugation at $10,000 \mathrm{rpm}$ for $10 \mathrm{~min}$ at $4{ }^{\circ} \mathrm{C}$. The supernatant was collected, stored, and the activities of the enzymes were determined. The experiments were performed in triplicate.

\subsection{Evaluation of the Effect of Cell-Free Enzyme Extracts and Semi-Purified Glucanase on Conidia Germination of T. paradoxa and C. gloeosporioides}

$W$. anomalus was grown for $24 \mathrm{~h}$ in YPD or MM broths using the inducer that gave the highest activity for both enzymes.

When the growth of $W$. anomalus was carried out in YPD medium, the culture was centrifuged, filtered, and 100, 80, 60, 40, and $20 \mu \mathrm{L}$ of the cell-free supernatant was placed in a 96-well plate, and the volume was brought to $300 \mu \mathrm{L}$ with fresh YPD medium. The solutions were inoculated with a $5 \mu \mathrm{L}$ conidial suspension of $4 \times 10^{4}$ spores/mL of each phytopathogen and incubated for $48 \mathrm{~h}$. Germination was calculated by measuring the optical density at $600 \mathrm{~nm}$ in each of the proposed systems using a microplate reader. The control was considered as $100 \%$ germination. To calculate the germination percentage, a direct comparison was made between the OD of the control and that of each condition.

For the growth of $W$. anomalus in MM broth medium, an extra purification or concentration step was performed using $10 \mathrm{kDa}$ cutoff Amicon ${ }^{\circledR}$ filters units (Centricon Merck-Millipore, Kenilworth, UK). This extra step was performed because, according to the results explained below, in this system 
only the glucanase activity was observed, which made it a better candidate for a semi-purification of the enzyme. Inhibition of conidia germination was tested under the same conditions as before.

\subsection{SDS-PAGE and Zymogram of the Semi-Purified Glucanase}

With the mycelium of T. paradoxa as an inducer, the $24 \mathrm{~h}$ MM culture media was centrifuged at $10,000 \mathrm{rpm}$ for five minutes at $4{ }^{\circ} \mathrm{C}$. Then, the supernatant was filtered and concentrated using $10 \mathrm{kDa}$ Amicon ${ }^{\circledR}$ filters units. The glucanase activity was measured as described above. The protein concentration was measured using the Biorad protein kit, and a 12\% SDS polyacrylamide gel was carried out as described by Laemmli, 1970 [35]. The gel was stained with a silver stain to detect the protein bands. For the zymogram, a $12 \%$ SDS polyacrylamide gel containing $0.03 \%$ laminarin was used and treated according to Hong et al. 2017 [36,37]. After the electrophoresis, the gel was washed with $50 \mathrm{mM}$ acetate, $\mathrm{pH} 5.0$, and incubated with Triton $2.5 \%$ for $30 \mathrm{~min}$, washed again, and incubated with the acetate buffer at $37^{\circ} \mathrm{C}$ for $2 \mathrm{~h}$ while stirring. Finally, the gel was rinsed with distilled water and submerged in a $0.15 \%$ 2,3,5-triphenyltetrazolium chloride solution and heated in a water bath at $90{ }^{\circ} \mathrm{C}$ until the activity bands appeared. Reaction of laminarin with the 2,3,5-triphenyltetrazolium reagent generates a color change that corresponds with the glucanolytic activity.

\subsection{Effect of the Crude Enzymatic Extract for the Protection of Post-Harvest Fruits}

Post-harvest cocoa pods from the state of Chiapas, México, were used for this experiment. Only the crude enzyme extract was used to evaluate its capacity to protect the fruits. To avoid possible interactions between phytopathogens, we decided to use T. paradoxa spores only, because it was the complementary carbon source used for the production of the enzyme extract.

The fruits were visually evaluated to identify their state of health, and the fruits with signs of disease or damage were discarded. The selected fruits were sanitized with sodium hypochlorite $(0.1 \% \mathrm{v} / \mathrm{v}$ for $10 \mathrm{~min})$ and were subsequently washed with sterile distilled water to remove the excess of hypochlorite. The cell-free extract was obtained from a culture of $W$. anomalus grown in PDB under the conditions mentioned before. Under sterile conditions, four wounds of approximately $5 \mathrm{~cm}$ long and $2 \mathrm{~cm}$ deep were made in the cacao fruits. At each of these points, $100 \mu \mathrm{L}$ of the cell-free extract was placed and subsequently inoculated with a suspension of $1 \times 10^{6}$ spores $/ \mathrm{mL}$ of T. paradoxa. The fruits were placed in humid chambers $\left(80 \%\right.$ relative humidity) at $28{ }^{\circ} \mathrm{C}$ for seven days. The fungal decay of the fruits was evaluated qualitatively. Three control fruits and three fruits inoculated with the cell-free extract were used.

\section{Results}

\subsection{W. anomalus Whole-Cells Inhibited the Growth of the Phytopathogenic Fungi}

$W$. anomalus reduced the growth of $C$. gloeosporioides by $18.7 \% \pm 3.85,43.1 \% \pm 2.20$, and $51.4 \% \pm 13.2$ on PDA, YPD, and MM, respectively (Figure 1A), in comparison with the controls. It also reduced the growth of $T$. paradoxa by $27 \% \pm 6.73,14.2 \% \pm 3.98$, and $36.1 \% \pm 11.5$ on PDA, YPD, and MM, respectively (Figure 1B), in comparison with their respective controls. The antagonistic effect showed a statistically significant difference according to a one-way ANOVA and Tukey's test $(p<0.05)$. According to the figure, the inhibition of $C$. gloeosporioides growth is probably related to the production of soluble metabolites, such as organic acids or enzymes, since the growth of the filamentous fungus stopped before contacting the yeast biomass. In the case of T. paradoxa, inhibition seems to be related to competition for space and nutrients. T. paradoxa in MM grew as a transparent mycelium that showed a certain degree of resistance to this competitive mechanism (Figure 1B). The antagonistic effect of $W$. anomalus against $C$. gloeosporioides was higher than in the case of $T$. paradoxa. 


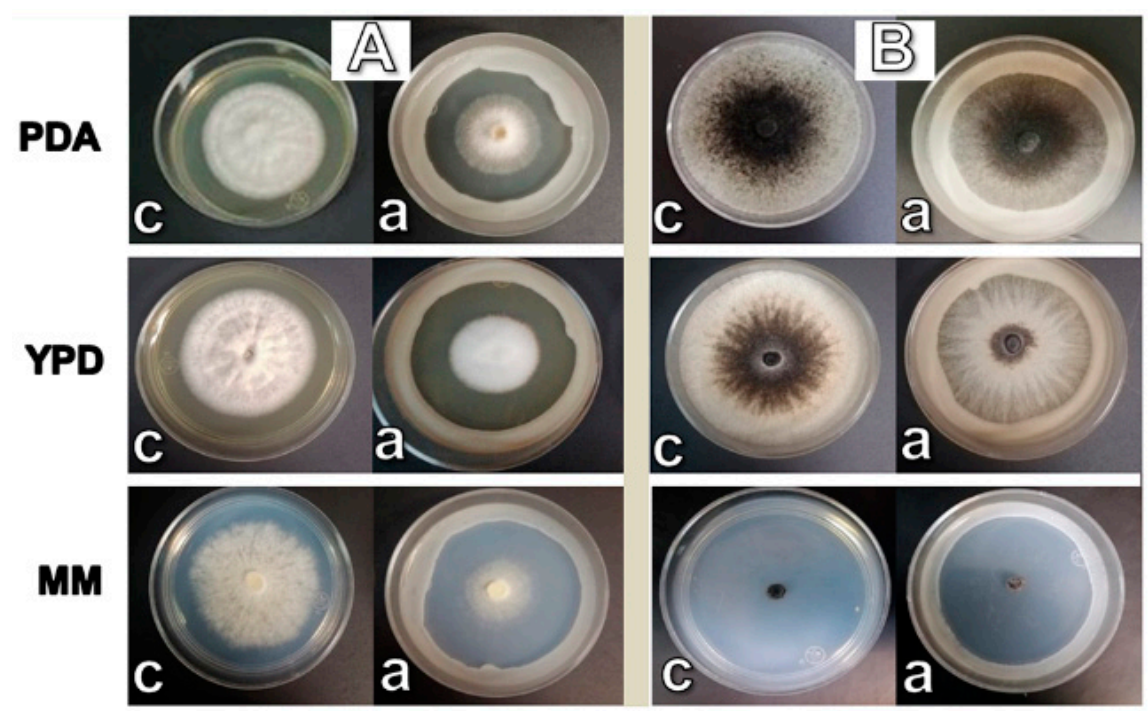

Figure 1. Effect of W. anomalus on the growth of C. gloeosporioides (A) and T. paradoxa (B). Growth was measured from the center to the limit of mycelium. Control (c) and with the antagonistic yeast (a).

\subsection{Effects of W. anomalus on Spore Germination of C. gloeosporioides and T. paradoxa in Liquid Media}

In the absence of the antagonist yeast, C. gloeosporioides (Figure 2A) and T. paradoxa (Figure 2B) developed mycelia in the three media (controls). However, in the presence of $W$. anomalus, inhibition of spore germination was observed with both phytopathogens, regardless of the media used. In the case of T. paradoxa, some germinated mycelium was observed in YPD medium (Figure 2B(2a)), which agrees with the possible mechanism of inhibition by competition that occurred in solid medium. Notably, the degree of germination of T. paradoxa spores in the presence of $W$. anomalus was less than in the control, which reinforces the strong inhibition of T. paradoxa germination by $W$. anomalus. In addition, T. paradoxa showed little germination and short mycelial growth in MM in the absence of the antagonist, which suggests that $\mathrm{MM}$ is not optimal for the growth of T. paradoxa.

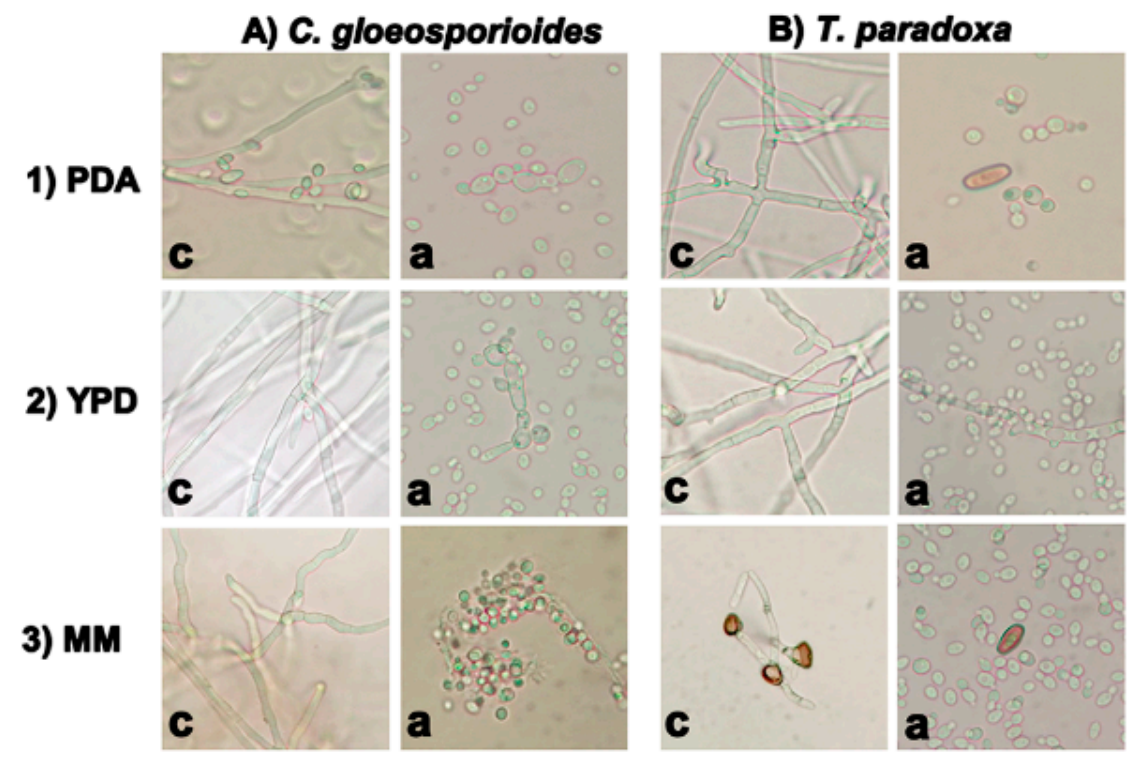

Figure 2. Inhibition of conidia germination of the phytopathogens in PDA (1), YPD (2), and MM (3) by $W$. anomalus. Controls with $4 \times 10^{4}$ spores/mL of each fungus (c) and the same number of spores in the presence of $10^{5}$ cells $/ \mathrm{mL}$ of $W$. anomalus (a). 


\subsection{Damage to the Phytopathogen Cell Wall Structures in Co-Culture with W. anomalus}

Figure 3 shows the mycelia of C. gloeosporioides (A) and T. paradoxa (B) in PDB, YPD, and MM media in the absence (c) or presence of W. anomalus (a). In the first case, mycelia were fully stained by the dye, indicating the integrity and viability of the cells. In the presence of $W$. anomalus, we observed large morphological changes of C. gloeosporioides and T. paradoxa mycelia and deficient staining of the cells. The greatest effect was observed for both phytopathogens in MM.

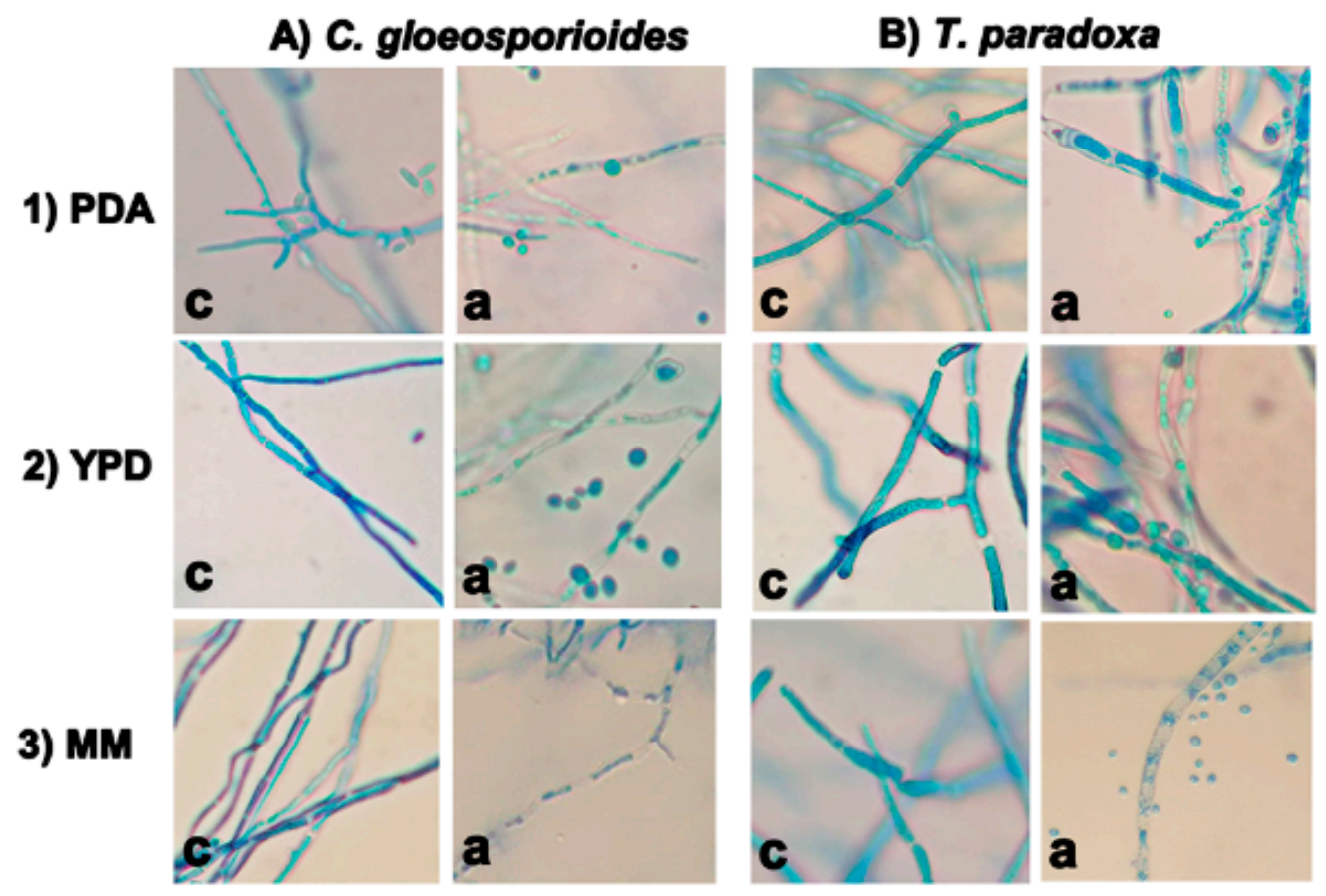

Figure 3. Structural damage of the cell-wall of $C$. gloeosporioides (A) and T. paradoxa (B) by W. anomalus in PDB (1), YPD (2), and MM (3) liquid media. The damage of the cell wall was evaluated qualitatively by staining the cells with lactophenol blue. $\mathrm{c}=$ control; $\mathrm{a}=$ yeast-treated mycelium.

\subsection{Production of Hydrolytic Enzymes by W. anomalus}

As shown in Figure 4, the highest chitinolytic activity was obtained in the presence of T. paradoxa mycelia biomass ( $47 \mathrm{U}$, with a statistically significant difference), followed by colloidal chitin with $(38 \mathrm{U})$ and without an inducer ( $36 \mathrm{U})$, which suggests that $W$. anomalus produces chitinase constitutively. When C. gloeosporioides biomass was present in the culture media, the chitinolytic activity was the same as that obtained with media containing colloidal chitin or without an inducer (34 U). In contrast, there was no significant difference in the glucanolytic activity produced by $W$. anomalus without an inducer (56 U), or in the presence of T. paradoxa mycelia (58 U), colloidal chitin (50 U) or C. gleosporioides mycelia (52 U). A one-way ANOVA and Tukey's test $(p<0.05)$ were performed to evaluate the statistical significance of the differences.

We further investigated if the production of chitinase and glucanase followed the same pattern in minimal media (MM) and YPD. As seen in Figure 5, in minimal media, only glucanase activity was present. The glucanase activity was the same in all cases, regardless of the presence or absence of inducers. However, there was a 37\% loss of activity compared to the complete media YPD (Figure 4). A remarkable difference was the absence of chitinase activity in minimal medium. Taken together, the complete medium should be used when the goal is to produce both hydrolytic enzymes from $W$. anomalus, but the minimal medium offers the advantage of obtaining only a single enzyme. A one-way ANOVA and Tukey's test $(p<0.05)$ did not show a statistically significant difference between the conditions. 


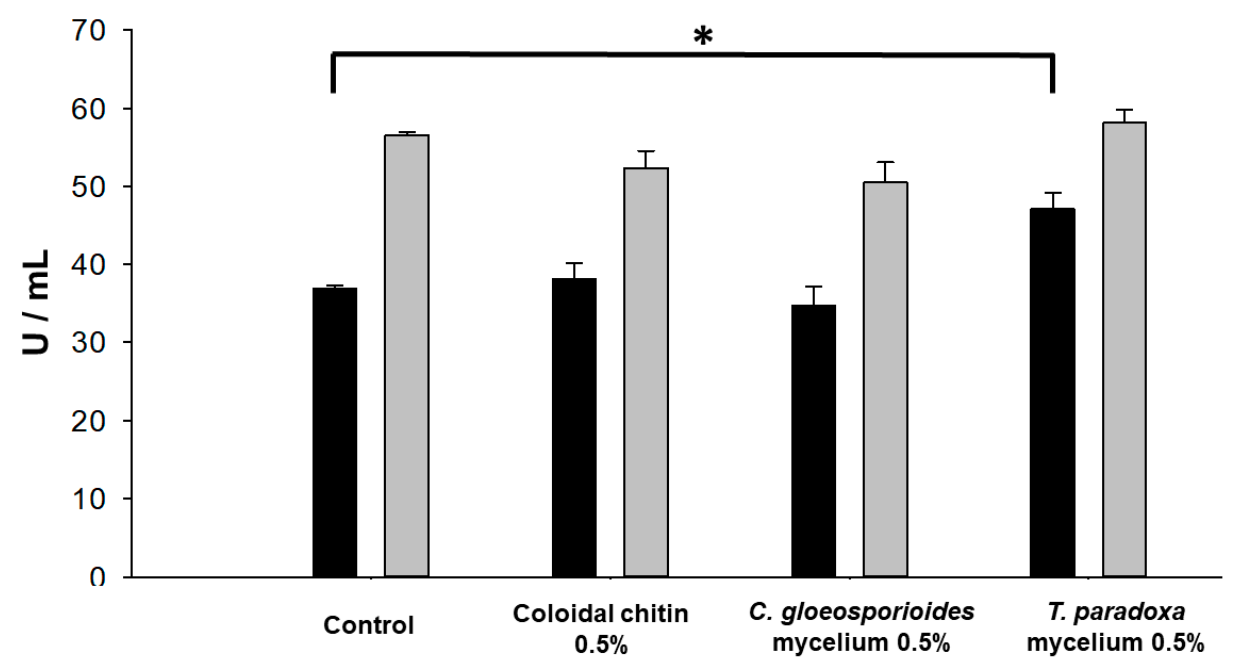

Figure 4. Extracellular chitinase (black) and glucanase (gray) activities of W. anomalus grown in YPD media with $0.5 \%(w / v)$ of different inducers. Asterisk $\left(^{*}\right)$ indicates a statistically significant difference $(p<0.05)$ between chitinase secretion in control and medium with T. paradoxa mycelium.

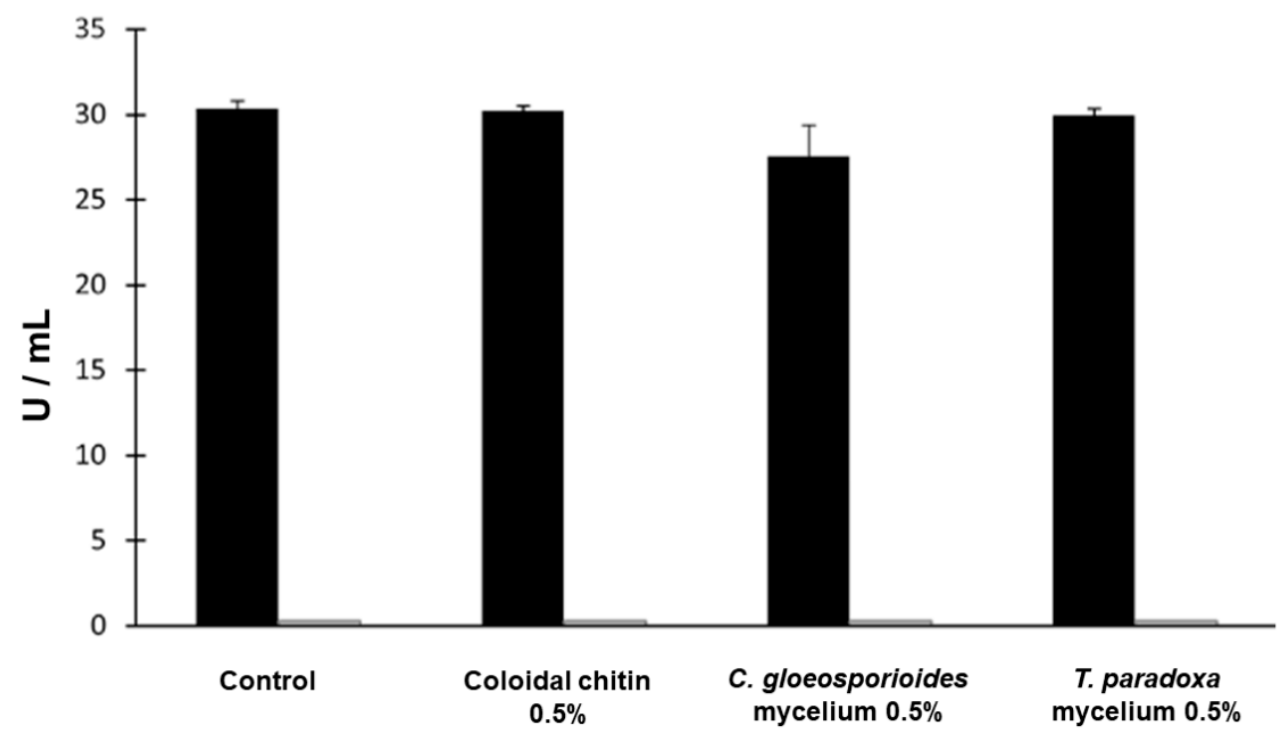

Figure 5. Extracellular glucanase (black) and chitinase (gray) activities secreted by W. anomalus in minimal media in the presence of $0.5 \%(w / v)$ of the different inducers. No chitinase activity was found in minimal media.

\subsection{Inhibition of Spore Germination by the Enzymes Produced in YPD (Glucanase and Chitinase) and MM (Glucanase)}

Next, we compared the inhibition of $C$. gloeosporioides and T. paradoxa germination by the chitinases and glucanases produced by W. anomalus in YPD. As shown in Figure 6, the cell-free supernatant inhibited C. gloeosporioides germination up to $72 \%$, and nearly $100 \%$ inhibition of T. paradoxa germination was obtained when using $31 \mathrm{U}$ of the combined enzymes.

To study the inhibition of germination by the glucanase produced by W. anomalus in MM with $0.5 \%(w / v)$ of T. paradoxa mycelia, a cell-free supernatant was concentrated with $10 \mathrm{kDa}$ cutoff Amicon ${ }^{\circledR}$ filter units. Glucanase activity was assayed with the concentrated supernatant from MM as described in the methods. Figure 7 shows that $13 \mathrm{U}$ of the enzyme inhibited $90 \%$ of T. paradoxa germination. Further addition of glucanase units did not increase the inhibition of T. paradoxa germination. 


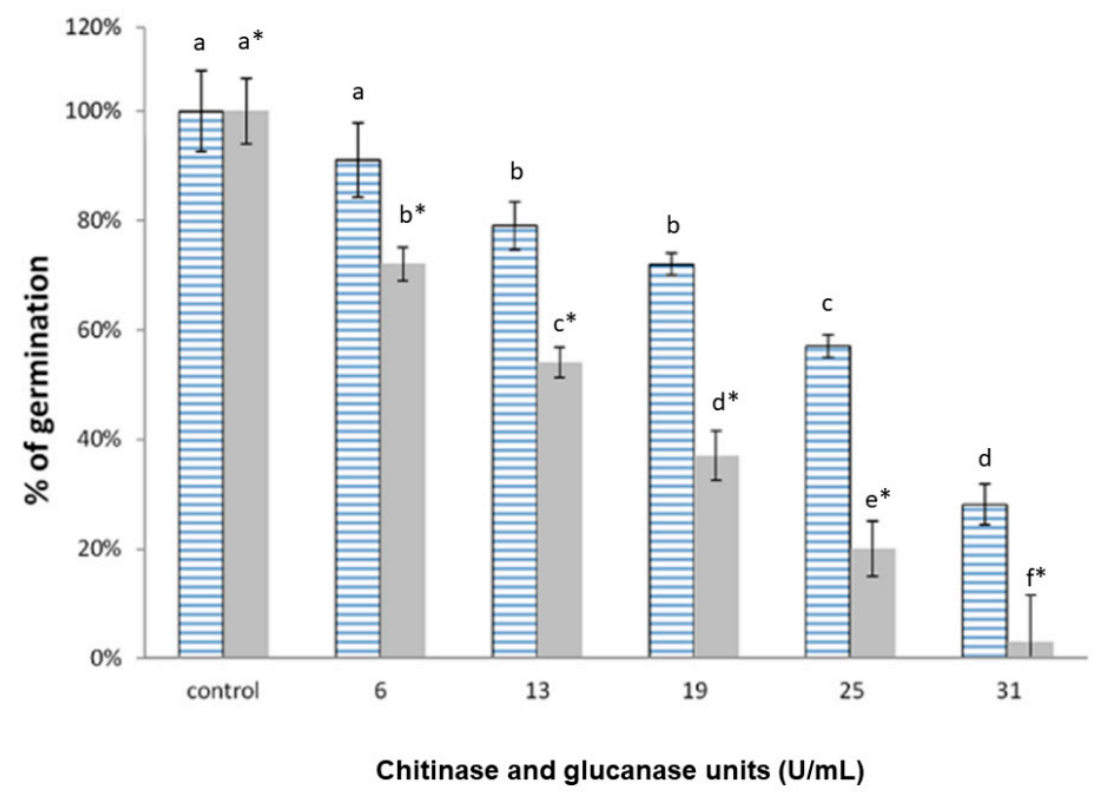

Figure 6. Inhibition of the conidia germination of C. gloeosporioides (blue lines) and T. paradoxa (gray) by different chitinase plus glucanase units from the YPD cell-free supernatants of W. anomalus and the T. paradoxa mycelia as an inducer. The units showed the sum of chitinase and glucanase activities. Different letters indicate statistically significant differences using one-way ANOVA and Tukey's test $(p<0.05)$.

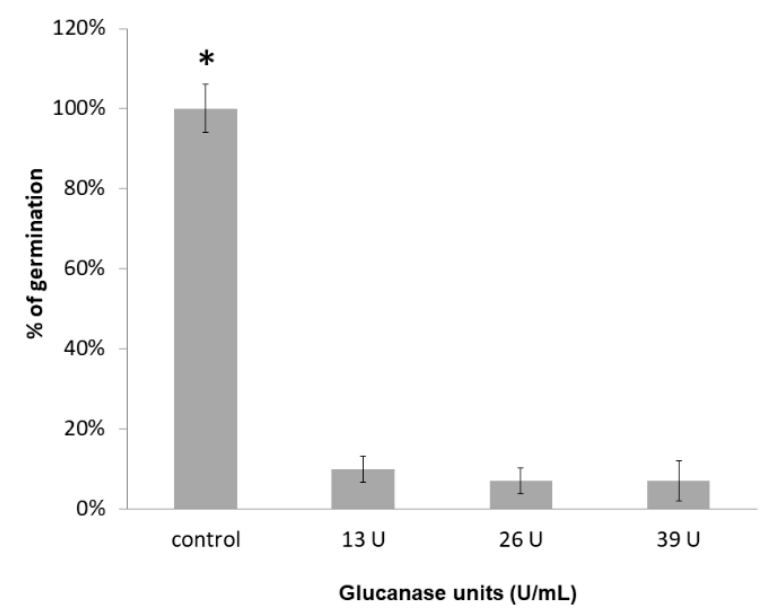

Figure 7. Inhibition of T. paradoxa conidia germination by different glucanolytic units from the cell-free supernatant of W. anomalus with $0.5 \%(w / v)$ of T. paradoxa mycelia as an inducer. Asterisk $\left.{ }^{*}\right)$ indicates statistically significant differences using a one-way ANOVA and Tukey's test $(p<0.05)$.

\subsection{Electrophoretic Analysis and Zymogram of the Glucanase Produced by W. anomalus in MM}

Electrophoresis of the concentrated supernatant followed by the determination of glucanase activity in the gel was carried out to obtain information on the molecular mass of the enzyme produced by W. anomalus in MM. The silver-stained gel shows that the amount of protein in the supernatant is quite low, and that protein is distributed in three minor bands (Figure 8A). We found two bands with a molecular mass close to $30 \mathrm{kDa}$. The zymogram showed just one band of $30 \mathrm{kDa}$ associated with the hydrolysis of the laminarin (Figure $8 \mathrm{~B}$ ), which is in agreement with the reported molecular mass of the enzyme [37]. 


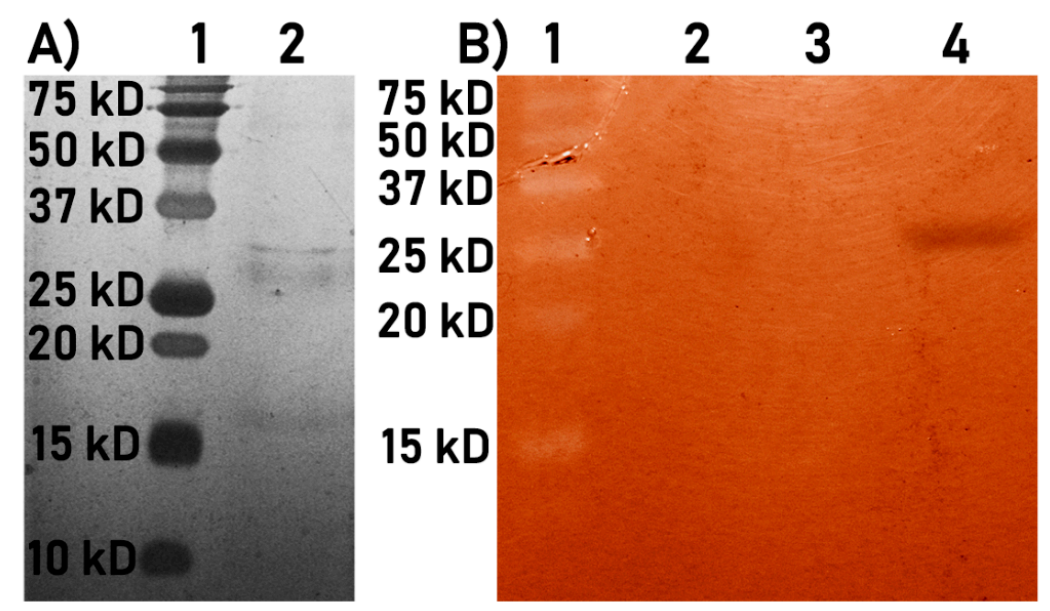

Figure 8. Silver-stained SDS-PAGE (A) and zymogram (B) of the cell-free supernatant of W. anomalus cultured in MM with T. paradoxa mycelium. (1A) Molecular weight marker, (2A) Cell-free supernatant of $W$. anomalus, (1B) Molecular weight marker, and (4B) Zymogram of the glucanolytic activity in the cell-free supernatant of $W$. anomalus.

\subsection{The Cell-Free Extract Is Effective for the Protection of Cacao Pods against T. paradoxa}

Figure 9 shows the protection of the cell-free extract against T. paradoxa in cacao fruits. In the control fruits (without cell-free extract) (Figure 9A), there were signs of disease, including a decrease in the quality of the fruit, darkening of the skin, and a decrease in the turgor of the fruit. Further, the presence of mycelia in the wounds (orange circles) were observed. In contrast, fruits treated with the crude extract (Figure 9B) maintained their quality during the incubation period. There was an increase in the darkening of the fruit, although the absence of mycelium in the wounds (orange circles) was noted. These results indicate the potential for in vivo use of the cell-free yeast extract for post-harvest fruit protection.

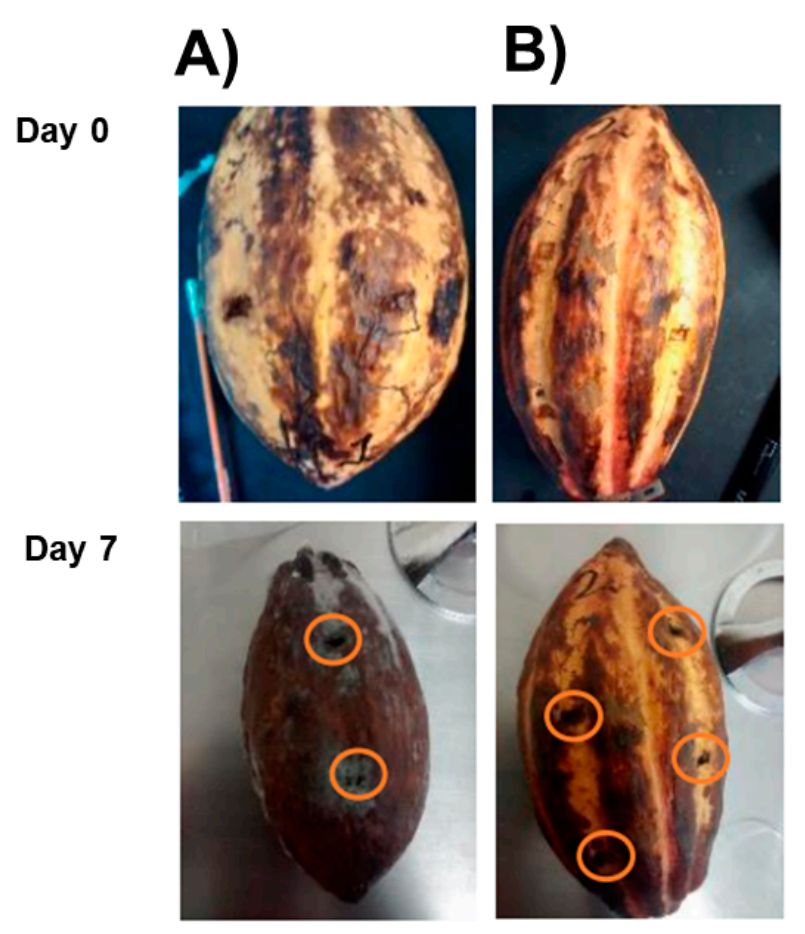

Figure 9. Effect of $W$. anomalus cell-free extract on cacao fruits infected by T. paradoxa. (A) Control without cell-free extract and (B) treatment with cell-free extract. The fruits were incubated for seven days at $28^{\circ} \mathrm{C}$ to evaluate their protective effect. 


\section{Discussion}

Yeasts have been used for biocontrol with a considerable safety range compared to bacteria and filamentous fungi [11]. The secretion of enzymes such as chitinases, exoglucanses, or proteases is a common trait during host-pathogen interactions [38,39]. In certain cases, antagonism is the result of enzymatic cell wall damage [28]. In this study, we focused on the influence of W. anomalus (Pichia anomala) against C. gloeosporioides and T. paradoxa and found two hydrolytic activities produced in two culture media. We chose these phytopathogens because they are important in the post-harvest infection of avocado and cacao pods, among other fruits, as emphasized in the introduction section. The impact of the diseases caused by these fungi in countries such as China, Mexico, and India is so important that up to $100 \%$ loss of fruit crops, such as the mango, have been reported when these fungi develop under certain humidity and temperature conditions [40]. (CP) (at $100 \mathrm{ng} \cdot \mathrm{mL}^{-1}$ final concentration)

Growth inhibition of both phytopathogens by W. anomalus was effective regardless of the medium used, either solid PDA, YPD or MM media. In agreement with this result, several studies have shown the ability of this yeast to generate biocontrol in rich media [36-39,41,42]. Biocontrol by W. anomalus is likely the result of the secretion and diffusion of metabolites in solid media, even under limited resources. We also detected a decrease in the growth of both phytopathogens in minimal media, especially for T. paradoxa, which had a large delay in the development of mycelium [43]. Inhibition of C. gloeosporioides and T. paradoxa germination by W. anomalus was observed in liquid YPD and minimal media, which could be explained by the secretion of lytic enzymes. In this sense, growth inhibition of several microorganisms by a fermentation product from $W$. anomalus was previously described, and this effect was attributed to antifungal compounds secreted into the culture media [44]. Sixty yeast species were tested for the inhibition of Penicillium roqueforti growth, and W. anomalus was the most effective because it produced cell wall degrading enzymes and different killer proteins [45]. While these tests were mainly made in rich media, in this study we found that the minimal media could provide enough resources for $W$. anomalus to generate metabolites that diffuse in solid media and generate antagonism against phytopathogens.

The lack of Cotton blue staining of both C. gloeosporioides and T. paradoxa mycelia induced by $W$. anomalus suggests that the extracellular hydrolytic enzymes produced by the yeast damaged the cell wall structures of both phytopathogens. In agreement with our results, Tayel et al. described the degradation of the cell wall in mixed cultures of W. anomalus and Aspergillus spp. [21]. Platania et al. reported damage to mycelia of $P$. digitatum, and described granulations and bending [46]. Moreover, Bhattacharya et al. used Cotton blue staining to observe the affected mycelia of Fusarium oxysporum by the action of hydrolytic enzymes from Bacillus pumilus [30].

The generation of extracellular hydrolytic enzymes is a common trait in fungal cells, and it is well known that these metabolites can be produced in rich media. In addition, the use of an inducer in some cases can increase the production of hydrolytic enzymes. Still, there are reports that some inducers might decrease the production of these enzymes. In the specific case of $W$. anomalus, two genes have been reported for extracellular glucanases (WaEXG1 and WaEXG2) when the yeast is grown in the presence of glucose and the cell walls of phytopathogenic fungi. In this context, it was determined that the WaEXG2 gene had a greater influence on the metabolism of the yeast, which could mean that the enzyme encoding by this gene plays a greater role in the biological control mechanism in $W$. anomalus [23]. Hong et al. reported that the use of colloidal chitin could lead to a decrease in the hydrolytic enzymes because it can affect the growth of W. anomalus, even in rich media [36]. In this study, three inducers were tested: colloidal chitin, $C$ gloeosporioides inactive biomass, and T. paradoxa biomass. We found that only T. paradoxa biomass in YPD induced a small increase in the production of hydrolytic enzymes by $W$. anomalus. Otherwise, it seems that the production of lytic enzymes was constitutive. This result could be due to the specific composition of the T. paradoxa cell wall [33]. On the other hand, one report showed that chitinase is regulated by a repressor/inducer system and is expressed only under certain conditions [13]. Frändberg and Schnürer also reported the lack of 
extracellular chitinases in media without some chitooligosaccharides [47]. It is possible that chitinases cannot be expressed in minimal media in comparison with the rich media.

Cell-free supernatants of the YPD media proved to be effective against both phytopathogens. Several authors also reported the potential use of cell-free supernatants against different phytopathogens. Inhibition by Bacillus subtilis against mold-generating fungi (Bortrytis cinerea, Penicillium digitatum) was reported using the cell-free supernatant produced in rich media [48]. Here, using the cell-free supernatants of YPD media containing mycelia biomass as inducer, we observed an inhibition of spore germination of both phytopathogens, resulting in $20 \%$ germination for C. gloeosporioides and just $3 \%$ for T. paradoxa. This result suggests that the hydrolytic enzymes produced by $W$. anomalus have a better efficiency compared to the results of Jiang et al. [49], showing that cell-free supernatants obtained from Pantoea dispersa cultured in PDB media inhibited between $33 \%$ and $36 \%$ of the spore germination of Ceratocytis fimbriata,. They also concluded that the extracellular metabolites of $P$. dispersa caused damage to the hyphae. Because rich media is expensive for the production of the hydrolytic enzymes, this study offers the possibility of using MM. W. anomalus cultured in MM secreted only glucanase, with $92 \%$ inhibition of spore germination. The biochemical data regarding the molecular mass is consistent with the results of other authors [36,37], which ensures the nature of the enzyme. Based on the results obtained, the enzymes produced by $W$. anomalus can be used to control the mycoparasites T. paradoxa and C. gloeosporioides under the experimental conditions. The trials should be extended to other parasites/crops to look for a broad-spectrum biocontrol agent.

\section{Conclusions}

The yeast $W$. anomalus secretes hydrolytic enzymes, even in the absence of an inducer. However, depending on the growth media, there is a differential expression of chitinase. The production of chitinase was detected in rich media, but not in minimal media, suggesting that some factors present in YPD media induce the synthesis of chitinase. Our results indicated that the best condition for the production of both hydrolytic enzymes in rich media by $W$. anomalus- 1446 was to include the mycelium of T. paradoxa. In minimal media, the production of glucanase was the same in all conditions. Extracellular enzymes inhibited spore germination $(>70 \%)$ and proved to be effective against both phytopathogens. Under in vivo conditions, the enzymatic extract was effective against the growth of T. paradoxa on cacao fruits. The secretion of glucanase by W. anomalus in minimal media is practical for the production of a single lytic enzyme at a low-cost.

Author Contributions: Conceptualization, G.G.-S., J.P.P. and D.R.O.-H.; methodology, L.F.Z.-G., D.R.O.-H., M.G.A.V.; formal analysis, L.F.Z.-G., G.G.-S., M.G.A.V., J.P.P.; funding acquisition G.G.-S., J.P.P.; resources, G.G.-S. and J.P.P.; writing —original draft preparation, L.F.Z.-G.; writing—review and editing, G.G.-S., J.P.P. and D.R.O.-H.; visualization, G.G.-S.; supervision, G.G.-S. and J.P.P.; project administration, G.G.-S.; funding acquisition, G.G.-S. and J.P.P. All authors have read and agreed to the published version of the manuscript.

Funding: This work was supported by CONACyT grants 256520 (GGS) and 254904 (JPP), SIP projects 20170864, 20190200 (GGS) and PAPIIT-DGAPA project IN222117 (JPP).

Acknowledgments: To CONACyT for provided the fellowship to the first author $\left(\mathrm{N}^{\mathrm{o}} 231581\right)$ and PIFI-IPN (BEIFI-IPN). First author was student of the Programa de Doctorado en Ciencias Qumicobiológicas, ENCB, IPN.

Conflicts of Interest: The authors declare no conflict of interest.

\section{References}

1. Dubey, N.K.; Singh, P.; Prakash, B.; Mishra, P.K. Plant Chemicals in Post-Harvest Technology for Management of Fungal, Mycotoxin and Insect Contamination of Food Commodities. In Biological Control. Progress in Biological Control; Mérillon, J., Ramawat, K., Eds.; Springer: Dordrecht, The Netherlands, 2012; Volume 12, pp. 195-208.

2. Liu, J.; Sui, Y.; Wisniewski, M.; Droby, S.; Liu, Y. Utilization of antagonistic yeasts to manage postharvest fungal diseases of fruit. Int. J. Food Microbiol. 2013, 167, 153-160. [CrossRef] [PubMed] 
3. Heydari, A.; Pessarakli, M. A Review on Biological Control of Fungal Plant Pathogens Using Microbial Antagonists. J. Biol. Sci. 2010, 10, 273-290. [CrossRef]

4. Sharma, R.; Singh, D.; Singh, R. Biological control of postharvest diseases of fruits and vegetables by microbial antagonists: A review. Biology 2009, 50, 205-221. [CrossRef]

5. Yang, C.; Hamel, C.; Vujanovic, V.; Gan, Y. Fungicide: Modes of action and possible impact on non target microorganisms. ISRN Ecol. 2011, 2011,1-8. [CrossRef]

6. Pal, K.; Mcspadden, B. Biological control of plant pathogens. Plant Health Instr. 2006, 11, 1-25. [CrossRef]

7. Droby, S.; Wisniewski, M.; Teixidó, N.; Spadaro, D.; Jijakli, M.H. The science, development, and commercialization of postharvest biocontrol products. Postharvest Biol. Technol. 2016, 122, 22-29. [CrossRef]

8. Chaverri, P.; Branco-Rocha, F.; Jaklitsch, W.; Gazis, R.; Degenkolb, T.; Samuels, G.J. Systematics of the Trichoderma harzianum species complex and the re-identification of commercial biocontrol strains. Mycologia 2015, 107, 558-590. [CrossRef]

9. Yien, T.; Yun, C. Chitinase and $\beta-1,3$-glucanase activities of Trichoderma harzianum in response towards pathogenic and non-pathogenic isolates: Early indications of compatibility in consortium. Biocatal. Agric. Biotechnol. 2015, 4, 109-113.

10. Haïssam, J.M. Pichia anomala in biocontrol for apples: 20 years of fundamental research and practical applications. Anton Leeuwenhoek Int. J. Gen. Mol. Microbiol. 2011, 99, 93-105. [CrossRef]

11. Freimoser, F.M.; Rueda-Mejia, M.P.; Tilocca, B.; Migheli, Q. Biocontrol yeasts: Mechanisms and applications. World J. Microbiol. Biotechnol. 2019, 35, 154-173. [CrossRef]

12. Zhang, D.; Spadaro, D.; Garibaldi, A.; Gullino, M.L. Potential biocontrol activity of a strain of Pichia guilliermondii against grey mold of apples and its possible modes of action. Biology 2011, 57, 193-201. [CrossRef]

13. Swiontek, B.M.; Jankiewicz, U.; Burkowska, A. Chitinolytic microorganisms and their possible application in environmental protection. Curr. Microbiol. 2014, 68, 71-81. [CrossRef] [PubMed]

14. Hartl, L.; Zach, S.; Seidl-Seiboth, V. Fungal chitinases: Diversity, mechanistic properties and biotechnological potential. Appl. Microbiol. Biotechnol. 2012, 93, 533-543. [CrossRef] [PubMed]

15. Diaz-Rincon, D.J.; Duque, I.; Osorio, E.; Rodriguez-Lopez, A.; Espejo-Mojica, A.; Parra-Giraldo, C.M.; Quevedo-Hidalgo, B. Production of recombinant Trichoderma reesei Cellobiohydrolase II in a new expression system based on Wickerhamomyces anomalus. Enzyme Res. 2017, 2017, 1-8. [CrossRef]

16. Aloui, H.; Licciardello, F.; Khwaldia, K.; Hamdi, M.; Restuccia, C. Physical properties and antifungal activity of bioactive films containing Wickerhamomyces anomalus killer yeast and their application for preservation of oranges and control of postharvest green mold caused by Penicillium digitatum. Int. J. Food Microbiol. 2015, 200, 22-30. [CrossRef]

17. Hashem, M.; Alamri, S.A.; Hesham, A.E.L.; Al-Qahtani, F.M.; Kilany, M. Biocontrol of apple blue mould by new yeast strains: Cryptococcus albidus KKUY0017 and Wickerhamomyces anomalus KKUY0051 and their mode of action. Biocontrol Sci. Technol. 2014, 24, 1137-1152. [CrossRef]

18. Chi, M.; Li, G.; Liu, Y.; Liu, G.; Li, M.; Zhang, X.; Sun, Z.; Sui, Y.; Liu, J. Increase in antioxidant enzyme activity, stress tolerance and biocontrol efficacy of Pichia kudriavzevii with the transition from a yeast-like to biofilm morphology. Biology 2015, 90, 113-119. [CrossRef]

19. Passoth, V.; Fredlund, E.; Druvefors, U.A.; Schnurer, J. Biotechnology, physiology and genetics of the yeast Pichia anomala. FEMS Yeast Res. 2006, 6, 3-13. [CrossRef]

20. Fredlund, E.; Blank, L.; Schnürer, J.; Sauer, U.; Passoth, V. Oxygen and glucose dependent regulation of central carbon metabolism in Pichia anomala. Appl. Environ. Microbiol. 2004, 70, 5905-5911. [CrossRef]

21. Tayel, A.; El-tras, W.; Moussa, S. Antifungal action of Pichia anomala against aflatoxigenic Aspergillus flavus and its application as a feed supplement. J. Sci. Food Agric. 2013, 93, 3259-3263. [CrossRef]

22. Zepeda, G.; Olicón-Hernández, D.R.; Martínez, C.; Guerra-Sánchez, G. Study of the action mode of Wickerhamomyces anomalus against Colletotrichum gloeosporioides. J. Agric. Sci. Technol. B 2016, 6, 341-349.

23. Parafati, L.; Cirvilleri, G.; Restuccia, C.; Wisniewski, M. Potential role of exoglucanase genes (WaEXG1 and WaEXG2) in the biocontrol activity of Wickerhamomyces anomalus. Microbiol. Ecol. 2017, 73, 876-884. [CrossRef] [PubMed]

24. Dean, R.; Van Kan, J.A.; Pretorius, Z.A.; Hammond-Kosack, K.E.; Di Pietro, A.; Spanu, P.D.; Foster, G.D. The Top 10 fungal pathogens in molecular plant pathology. Mol. Plant Pathol. 2012, 13, 414-430. [CrossRef] 
25. Aiello, D.; Carrieri, R.; Guarnaccia, V.; Vitale, A.; Lahoz, E.; Polizzi, G. Characterization and pathogenicity of Colletotrichum gloeosporioides and C. karstii causing preharvest disease on Citrus sinensis in Italy. J. Phytopathol. 2015, 163, 168-177. [CrossRef]

26. Wijesinghe, C.J.; Wijeratnam, R.W.; Samarasekara, J.K.R.R.; Wijesundera, R.L.C. Biological control of Thielaviopsis paradoxa on pineapple by an isolate of Trichoderma asperellum. Biol. Control 2010, 53, 285-290. [CrossRef]

27. Pardo-De la Hoz, C.J.; Calderón, C.; Rincón, A.M.; Cárdenas, M.; Danies, G.; López-Kleine, L.; Jiménez, P. Species from the Colletotrichum acutatum, Colletotrichum boninense and Colletotrichum gloeosporioides species complexes associated with tree tomato and mango crops in Colombia. Plant Pathol. 2016, 65, 227-237. [CrossRef]

28. Sanchez, V.; Rebolledo, O.; Picaso, R.M.; Cardenas, E.; Cordova, J.; Gonzalez, O.; Samuels, G.J. In vitro antagonism of Thielaviopsis paradoxa by Trichoderma longibrachiatum. Mycopathologia 2007, 163, 49-58. [CrossRef]

29. Felestrino, É.; Santiago, I.; Freitas, L.; Rosa, L.; Ribeiro, S.; Moreira, L. Plant growth promoting bacteria associated with Langsdorffia hypogaea-rhizosphere-host biological interface: A neglected model of bacterial prospection. Front. Microbiol. 2017, 8, 172-187. [CrossRef] [PubMed]

30. Bhattacharya, S.; Das, A.; Samadder, S.; Rajan, S.S. Biosynthesis and characterization of a thermostable, alkali-tolerant chitinase from Bacillus pumilus JUBCH08 displaying antagonism against phytopathogenic Fusarium oxysporum. 3 Biotech 2016, 6, 87-95. [CrossRef] [PubMed]

31. Ramada, M.; Lopes, F.; Ulhoa, C.; Silva, R. Optimized microplate beta-1,3-glucanase assay system for Trichoderma spp. screening. J. Microbiol. Methods 2010, 81, 6-10. [CrossRef]

32. Miller, G.L. Use of Dinitrosalicylic Acid Reagent for Determination of Reducing Sugar. Anal. Chem. 1959, 31, 426-428. [CrossRef]

33. Gubbins, P.O.; Anaissie, E.J. Antifungal Therapy. Clinical Mycology, 2nd ed.; Churchill Livingstone: London, UK, 2009; pp. 161-195.

34. Murthy, N.S.; Bleakley, B.H. Simplified method of preparing colloidal chitin used for screening of chitinase-producing microorganisms. J. Microbiol. 2012, 10, 1-5.

35. Laemmli, U. Cleavage of structural proteins during the assembly of the head of bacteriophage T4. Nature 1970, 227, 680-685. [CrossRef]

36. Hong, S.; Song, Y.; Seo, S.; Kim, K.; Jung, W. Antifungal activity and expression patterns of extracellular chitinases and b-1,3-glucanase in Wickerhamomyces anomalus EG2 treated with chitin and glucan. Microb. Pathog. 2017, 110, 159-164. [CrossRef]

37. Hong, S.; Song, Y.; Seo, S.; Kim, K.; Jung, W. Enzyme activity and expression pattern of intra-and extracellular chitinase and-1,3-glucanase of Wickerhamomyces anomalus EG2 using glycol chitin and glucan-containing high polymer complex. Int. J. Biol. Macromol. 2017, 105, 410-415. [CrossRef]

38. Zajc, J.; Gostincar, C.; Cernosa, A.; Gunde-Cimerman, N. Stress-tolerant yeasts: Opportunistic pathogenicity versus biocontrol potential. Genes 2019, 10, 42. [CrossRef]

39. Klein, M.N.; Kupper, K.C. Biofilm production by Aureobasidium pullulans improves biocontrol against sour rot in citrus. Food Microbiol. 2018, 69, 1-10. [CrossRef]

40. Kamle, M.; Kumar, P. Colletotrichum gloeosporioides: Pathogen of anthracnose disease in Mango (Mangifera indica L.). In Current Trends in Plant Disease Diagnostics and Management Practices; Kumar, P., Gupta, V., Tiwari, A., Kamle, M., Eds.; Springer: Cham, Germany, 2016; Volume 1, pp. 207-2019.

41. Xu, H.; Nobile, C.J.; Dongari-Bagtzoglou, A. Glucanase induces filamentation of the fungal pathogen Candida albicans. PLoS ONE 2013, 8, e63736. [CrossRef]

42. Tay, S.T.; Lim, S.L.; Tan, H.W. Growth inhibition of Candida species by Wickerhamomyces anomalus mycocin and a lactone compound of Aureobasidium pullulans. BMC Complement. Altern. Med. 2014, 14, 439-450. [CrossRef]

43. Cibelli, F.; Bevilacqua, A.; Raimondo, M.L.; Campaniello, D.; Carlucci, A.; Ciccarone, C.; Sinigaglia, M.; Corbo, M.R. Evaluation of fungal growth on olive-mill wastewaters treated at high temperature and by high-pressure homogenization. Front. Microbiol. 2017, 8, 2515-2524. [CrossRef]

44. Coda, R.; Cassone, A.; Rizzello, C.G.; Nionelli, L.; Cardinali, G.; Gobbetti, M. Antifungal activity of Wickerhamomyces anomalus and Lactobacillus plantarum during sourdough fermentation: Identification of novel compounds and long-term effect during storage of wheat bread. Appl. Environ. Microbiol. 2011, 77, 3484-3492. [CrossRef] 
45. Druvefors, U.A.; Passoth, V.; Schnürer, J. Nutrient effects on biocontrol of Penicillium roqueforti by Pichia anomala J121 during airtight storage of wheat. Appl. Environ. Microbiol. 2005, 71, 1865-1869. [CrossRef]

46. Platania, C.; Restuccia, C.; Muccilli, S.; Cirvilleri, G. Efficacy of killer yeasts in the biological control of Penicillium digitatum on Tarocco orange fruits (Citrus sinensis). Food Microbiol. 2012, 30, 219-225. [CrossRef]

47. Frändberg, E.; Schnürer, J. Chitinolytic properties of Bacillus pabuli K1. J. Appl. Bacteriol. 1994, 76, 361-367. [CrossRef]

48. Ambrico, A.; Trupo, M. Efficacy of cell free supernatant from Bacillus subtilis ET-1, an Iturin A producer strain, on biocontrol of green and gray mold. Postharvest Biol. Technol. 2017, 134, 5-10. [CrossRef]

49. Jiang, L.; Jeong, J.C.; Lee, J. Potential of Pantoea dispersa as an effective biocontrol agent for black rot in sweet potato. Sci. Rep. 2019, 9, 16354-16367. [CrossRef]

(C) 2020 by the authors. Licensee MDPI, Basel, Switzerland. This article is an open access article distributed under the terms and conditions of the Creative Commons Attribution (CC BY) license (http://creativecommons.org/licenses/by/4.0/). 